\title{
Characteristics of the Equatorial Electrojet determined from an array of magnetometers in N-NE Brazil
}

\author{
A. Rigoti ${ }^{1,3}$, F. H. Chamalaun ${ }^{1}$, N. B. Trivedi ${ }^{2}$, and A. L. Padilha ${ }^{2}$ \\ ${ }^{1}$ School of Earth Sciences, Flinders University of South Australia, G.P.O. Box 2100, Adelaide, S.A., 5001, Australia \\ ${ }^{2}$ Instituto Nacional de Pesquisas Espaciais - INPE, C.P. 515, 12201-970 São José dos Campos, S.P., Brazil \\ ${ }^{3}$ Now at Dep. Geologia, Universidade Federal do Parana, C.P. 19011, Curitiba, PR, CEP81531-990, Brazil
}

(Received August 2, 1997; Revised August 17, 1998; Accepted September 9, 1998)

\begin{abstract}
An array of 29 vector magnetometers was operated in N-NE Brazil from November 1990 until March 1991. We present the analysis of 16 selected quiet days, for which a simple model of an equivalent current distribution for the $S q$ and EEJ, fits the observed maximum amplitude of the daily variation at midday.

In equatorial regions the precise latitude profile of the $S q$ field is masked by the EEJ. This uncertainty is resolved by assuming that the EEJ, obtained after subtracting the $S q$ from the daily ranges, should present a ratio of 0.3 for the westward to eastward current. With this constraint, a combined non-linear least squares inversion of $S q$ and EEJ was used to estimate the parameters of Onwumechili's model of the EEJ current distribution. The $H$ and $Z$ components of the EEJ are jointly inverted and good agreement obtained between the calculated and observed data for all 16 days.

The EEJ's main parameters averaged for 16 quiet days were: A total positive current intensity equal to $67 \pm 20$ $\left(10^{3} \mathrm{~A}\right.$ ) for diurnal range $\mathrm{M}_{4}$ (or $80 \pm 20\left(10^{3} \mathrm{~A}\right)$ for $\left.\mathrm{M}_{3}\right)$ and a half-width of $403 \pm 67 \mathrm{~km}$. The EEJ centre was located at $21 \pm 16 \mathrm{~km}$ south of the dip equator. The $S q$ was estimated from several permanent observatories and found to be centred at a mean latitude of $5.5 \pm 2$ degrees south.
\end{abstract}

\section{Introduction}

In equatorial regions the normal quiet day $(S q)$ variation of the geomagnetic field shows a strong enhancement which is attributed to a narrow electrical current sheet flowing eastward along the magnetic dip equator and termed the Equatorial Electrojet (EEJ) (Chapman, 1951a). Its associated magnetic fields are only observed in a zone approximately $12^{\circ}$ on either side of the magnetic dip equator (Fig. 1A). In this zone a ground magnetic observatory records the vector sum of four different magnetic fields: the external and internal components of the $S q$ field and the external and internal EEJ fields. By " $S q$ " we mean the smoothed, global-scale magnetic diurnal variation excluding the EEJ. The external components are the fields directly attributed to the current systems in the ionosphere, whereas the internal component arises from currents induced in the sub-surface by the overhead current systems. The former provide information on the condition of the ionosphere whereas the latter reflects the electrical conductivity structure of the earth at depth. In this communication we attempt a separation of all four fields for a region in NNE Brazil (Fig. 1) using ground observations and a novel joint $S q$ and EEJ inversion procedure. In addition we obtained precise estimates of the parameters that characterise the model of the EEJ current system as proposed by Onwumechili (1967).

South America and Africa are the only two areas of the world where the EEJ zone crosses a continent such that it

Copy right(c) The Society of Geomagnetism and Earth, Planetary and Space Sciences (SGEPSS); The Seismological Society of Japan; The Volcanological Society of Japan; The Geodetic Society of Japan; The Japanese Society for Planetary Sciences. can be studied by ground stations across its entire width. The magnetic equator crosses the west coast of South America approximately $13^{\circ}$ south of the equator and then curves north to cross the geographic equator just off the NNE coast of Brazil (Fig. 1A). The relative position and orientation of the magnetic and geographic equators are important parameters, because the electrojet behaviour is governed by the dip equator, whereas the $S q$ is better represented as a function of the mean between geographic and dip latitudes (Onwumechili, 1967). In NNE Brazil, the angle between the magnetic and geographic equators is approximately $30^{\circ}$. This causes the EEJ and $S q$ to combine in a complicated manner. As a large part of Brazil is under the influence of the EEJ a practical reason for modelling the EEJ fields is to assess the effect that spatial inhomogeneities of the electrojet magnetic fields may have on high resolution aeromagnetic surveys.

The geomagnetic observatory of Huancayo played a crucial role in the discovery and earliest studies of the equatorial electrojet (Bartels and Johnston, 1940a,b; Egedal, 1947, 1948; Chapman, 1948, 1951a,b). It was also on the west coast of South America that the first detailed latitude profile across the EEJ was made by recording magnetic variations with a line array of 3-component stations (Forbush and Casaverde, 1961). In Brazil a profile study was conducted in 1971 by Hesse (Hesse, 1982). Among other findings, Hesse's work highlighted the minima in the latitude profile of the northward component of EEJ's magnetic field and he suggested that the internal part of the magnetic field related to the electrojet was very small. Only a few other EEJ morphological studies have been conducted in Brazil, based on 

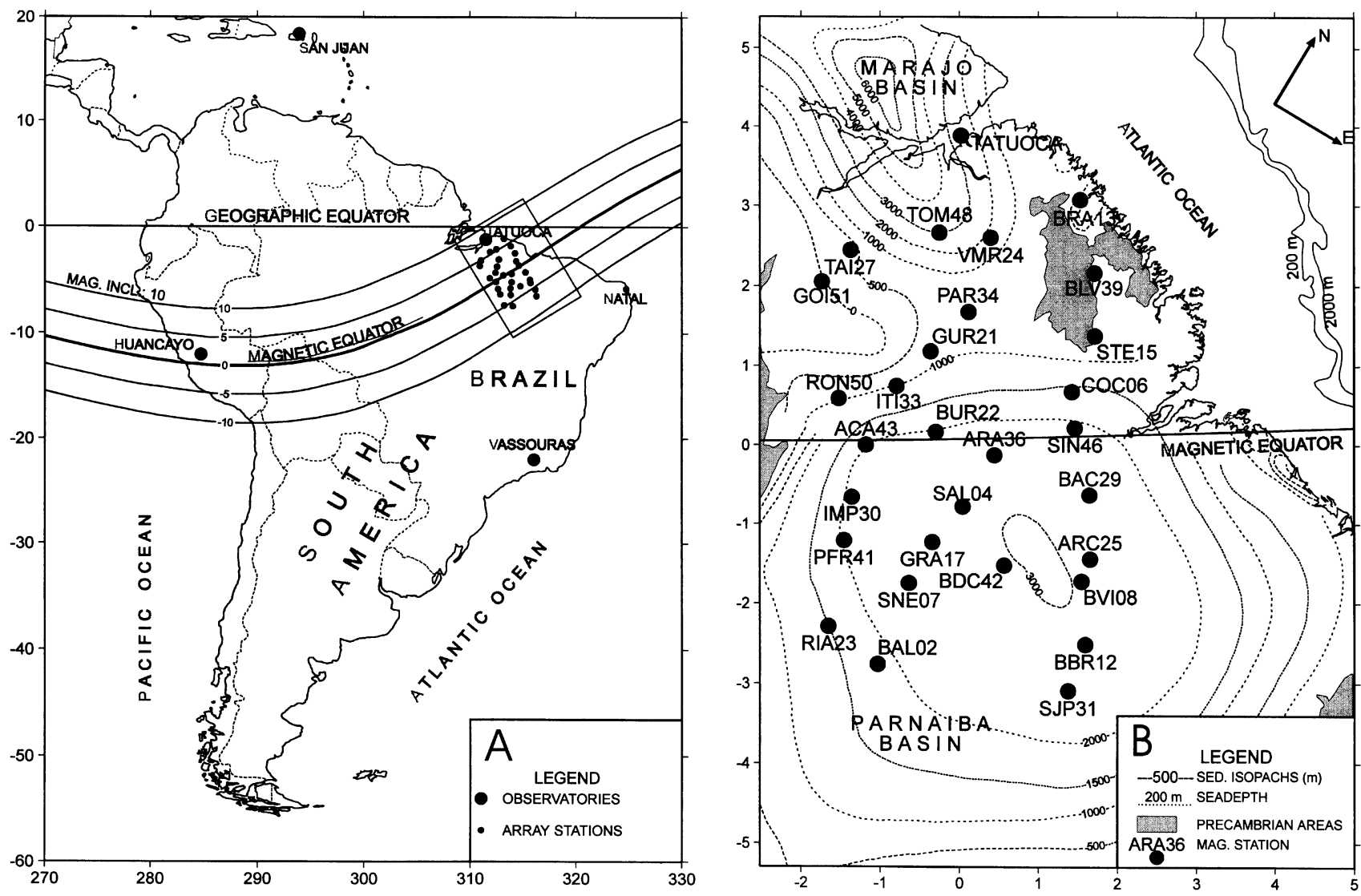

Fig. 1. (A) Location of the array relative to the magnetic equator in South America. (B) Enlarged map of the array station sites in NNE Brazil against the background of the major geological units. Note the coordinate system has been rotated such that the horizontal axis is parallel to the magnetic equator.

isolated temporary and permanent observatories. These studies compared the longitudinal variations in Huancayo with NNE Brazil (Kane and Trivedi, 1980, 1982, 1985; Kane, 1987). They showed a distinctive behaviour of the EEJ in NE Brazil in terms of amplitude, width, time of maximum and relation of the EEJ with the $S q$, emphasising the need for further investigations in this region. More recently, Stoerzel (1996) used single-station EEJ magnetic field variations observed in NE Brazil to estimate the $Z / H$ transfer functions for comparison with the magnetotelluric impedances.

For the present study, 29 temporary magnetometer stations were set up in NNE Brazil (Fig. 1B) to provide for the first time a detailed spatial and temporal record of the morphology of the EEJ in the Brazilian equatorial region. The array was deployed as a cooperative project between the Flinders University of South Australia and the Instituto Nacional de Pesquisas Espaciais (INPE).

\section{Data Acquisition}

The Flinders portable vector magnetometer as described in Chamalaun and Walker (1982) was used in the data acquisition. The current version of the magnetometer differs from the earlier model in that recording is now in solid state memory rather than on magnetic tape and the $\mathrm{A} / \mathrm{D}$ circuit has been modified to eliminate the need for backing off fields (Chamalaun and McKnight, 1993). The magnetic variations were recorded at one minute intervals and with $1 \mathrm{nT}$ resolution.

The array comprising 29 stations (Fig. 1B) was designed to be roughly rectangular with the long side perpendicular to the dip equator as determined from the IGRF. The average spacing was approximately $100 \mathrm{~km}$ and the area covered extends from $0^{\circ}$ to $8^{\circ} \mathrm{S}$ and $43^{\circ}$ to $49^{\circ} \mathrm{W}$. Data from the observatory at Tatuoca as well as the Flinders magnetometer installed in Natal, $800 \mathrm{~km}$ south of the dip equator, are also included in this study.

Recording started on 22 November 1990 and all instruments were recovered by the end of March 1991. Only three stations (ACA43, IMP30 and VMR24) failed to record adequate data. The station details are given in Table 1 .

To be able to improve our estimate of the spatial variation of the $S q$ we have extended the meridional spread by including data from the permanent observatories of the USGS network and from Vassouras in Brazil.

\section{Data Selection and Preparation}

To study the electrojet, magnetically quiet days should be selected to ensure that the diurnal variation consists of the magnetic field variations due to the EEJ and to the $S q$ only. In the present study an initial selection of 28 quiet days was made based on the planetary $Q$ index (Coffey, 1991) but subsequent visual inspection of magnetograms reduced that selection to 16 days.

It is instructive to examine the stacked magnetograms. 
Table 1. Station details.

\begin{tabular}{|c|c|c|c|c|c|c|c|}
\hline $\begin{array}{c}\text { Station } \\
\text { id. }\end{array}$ & Locality & $\begin{array}{l}\text { Latitude } \\
\text { (Deg. S) }\end{array}$ & $\begin{array}{c}\text { Longitude } \\
\text { (Deg. W) }\end{array}$ & $\begin{array}{c}\text { Distance } \\
(\mathrm{km})\end{array}$ & $\begin{array}{l}\text { Magnetic } \\
\text { inclination }\end{array}$ & $\begin{array}{c}\text { Dip } \\
\text { latitude }\end{array}$ & $\begin{array}{l}\text { Mean } \\
\text { latitude }\end{array}$ \\
\hline NAT40 & Natal & -5.8 & 35.2 & -791.49 & -15.636 & -7.97 & -6.9 \\
\hline SJP30 & S. J. dos Patos & -6.48 & 43.76 & -331.99 & -6.678 & -3.35 & -4.92 \\
\hline BAL02 & Balsas & -7.44 & 46.00 & -288.72 & -5.843 & -2.93 & -5.19 \\
\hline BBR12 & Buriti Bravo & -5.88 & 43.88 & -268.42 & -5.5 & -2.76 & -4.32 \\
\hline RIA23 & Riachão & -7.35 & 46.78 & -234.51 & -4.803 & -2.41 & -4.88 \\
\hline BV108 & Boa Vista & -5.22 & 44.32 & -180.63 & -3.891 & -1.95 & -3.59 \\
\hline SNE07 & Serra Negra & -6.37 & 46.19 & -177.16 & -3.75 & -1.88 & -4.12 \\
\hline $\mathrm{BDC} 42$ & Barra do Corda & -5.56 & 45.27 & -155.44 & -3.338 & -1.67 & -3.61 \\
\hline $\mathrm{ARC} 25$ & Gov. Archer & -4.93 & 44.38 & -149.88 & -3.258 & -1.63 & -3.28 \\
\hline GRA17 & Grajaú & -5.77 & 46.20 & -120.53 & -2.704 & -1.35 & -3.56 \\
\hline PFR41 & Porto Franco & -6.33 & 47.16 & -115.43 & -2.573 & -1.29 & -3.81 \\
\hline SAL04 & Santa Luzia & -5.19 & 46.10 & -71.65 & -1.791 & -0.9 & -3.05 \\
\hline BAC29 & Bacabal & -4.24 & 44.80 & -60.12 & -1.58 & -0.79 & -2.51 \\
\hline ARA36 & Arame & -4.42 & 46.09 & 0 & -0.429 & -0.21 & -2.32 \\
\hline BUR22 & Buriticupu & -4.55 & 46.88 & 34.49 & 0.229 & 0.11 & -2.22 \\
\hline SIN46 & Santa Inês & -3.60 & 45.39 & 35.13 & 0.232 & 0.12 & -1.74 \\
\hline RON50 & Rondon do Pará & -4.82 & 48.15 & 84.65 & 1.17 & 0.59 & -2.12 \\
\hline $\mathrm{COC} 06$ & Cocalinho & -3.23 & 45.66 & 86.41 & 1.236 & 0.62 & -1.3 \\
\hline ITI33 & Itinga & -4.31 & 47.60 & 100.02 & 1.418 & 0.71 & -1.8 \\
\hline GUR21 & Gurupizinho & -3.72 & 47.46 & 147.48 & 2.363 & 1.18 & -1.27 \\
\hline STE15 & Santa Teresa & -2.48 & 45.78 & 163.43 & 2.68 & 1.34 & -0.57 \\
\hline PAR34 & Paragominas & -3.05 & 47.30 & 201.24 & 3.331 & 1.7 & -0.67 \\
\hline GOI51 & Goianésia & -3.68 & 49.08 & 247.69 & 4.142 & 2.07 & -0.8 \\
\hline BLV39 & Bela Vista & -1.81 & 46.19 & 250.77 & 4.315 & 2.16 & 0.18 \\
\hline TAL27 & Tailândia & -3.15 & 48.97 & 290.43 & 4.959 & 2.48 & -0.34 \\
\hline TOM48 & Tomé-Açu & -2.36 & 48.13 & 314.54 & 5.404 & 2.71 & 0.18 \\
\hline BRA13 & Bragança & -1.12 & 46.81 & 352.88 & 6.196 & 3.11 & 1 \\
\hline TAT & Tatuoca & -1.2 & 48.5 & 445.73 & 7.867 & 3.95 & 1.38 \\
\hline VAS & Vassouras & -22.4 & 43.6 & & -31.08 & -16.77 & -19.59 \\
\hline SJG & San Juan & 18.1 & 66.2 & & 47.12 & 28.30 & 23.25 \\
\hline DLR & Del Rio & 29.3 & 100.8 & & 58.12 & 38.80 & 34.05 \\
\hline TUC & Tucson & 32.2 & 110.8 & & 58.94 & 39.70 & 35.95 \\
\hline BSL & Bay St Louis & 30.4 & 89.6 & & 60.94 & 41.98 & 36.19 \\
\hline FRN & Fresno & 37.1 & 119.7 & & 61.59 & 42.74 & 39.92 \\
\hline FRD & Fredericksburg & 38.2 & 77.4 & & 67.55 & 50.42 & 44.31 \\
\hline $\mathrm{BOU}$ & Boulder & 40.1 & 105.2 & & 67.26 & 50.02 & 45.06 \\
\hline NEW & Newport & 48.3 & 117.1 & & 71.45 & 56.13 & 52.22 \\
\hline SIT & Sitka & 57.1 & 135.3 & & 73.94 & 60.07 & 58.59 \\
\hline
\end{tabular}

Where: Magnetic inclination $I$ is determined from IGRF for January 1991. The dip latitude is computed from $\delta=\arctan ((\tan I) / 2)$ and the mean latitude from $m=(\phi+\delta) / 2$, where $\phi$ is the N-latitude. 
In Fig. 2 we have shown the horizontal magnetograms for the 16 days for a single station (BUR22) as a function of local time. The main points to note are:

a) At midnight, the traces are close to a straight line, showing no significant magnetic variation. Hence, the midnight value or the mean between the preceding and subsequent midnight values can be taken as the zero reference level for the diurnal variation. Note that $H$ and $Z$ field intensities henceforth have the same meaning as $\Delta H$ and $\Delta Z$ when measured with respect to the midnight level.

b) The day-to-day variability in amplitude.

c) A counter-electrojet field variation (CE), as evidenced by the negative excursion of the trace on 7 January 1991, centred at 08:00 hours and lasting for some four hours.

d) The changes in the time of maximum, which lies between 12:00 and 14:00 hours in the first set of days until 7 January but between 10:00 and 12:00 hours in the remaining days, except for 6 February when the maximum

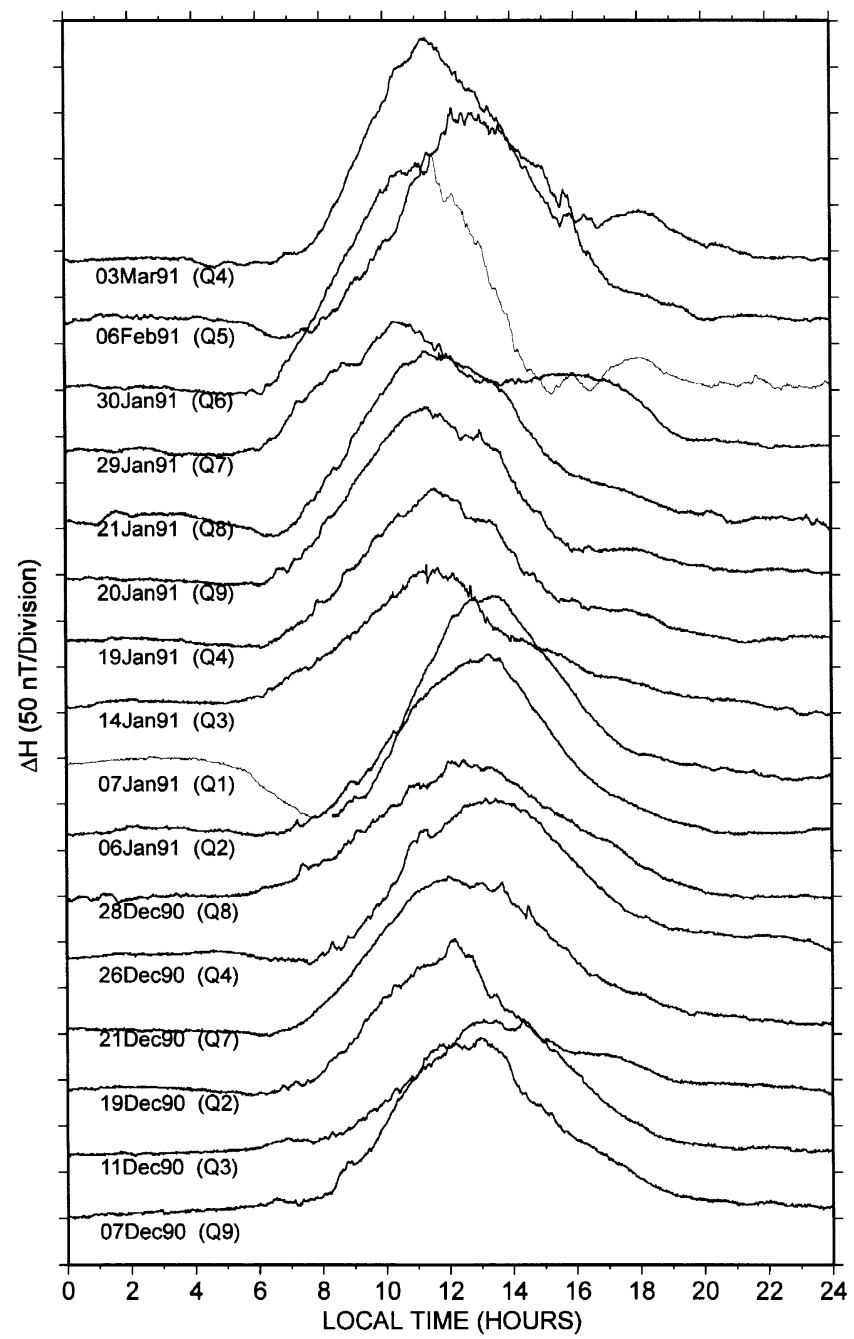

Fig. 2. Stacked $H$ component magnetograms for the 16 selected quiet days at station BUR22. The dates are identified along each trace and also the global $Q$ index for the date. occurs again between 12:00 and 14:00 hours.

e) Most records show small disturbances at around noon, but a few show a major disturbance in the afternoon, as for example on 29 and 30 January.

f) The asymmetry with respect to the maximum of $H$. In most of the quiet days, the rate of decay in the afternoon is smaller than the rate of the morning increase.

These features are commonly observed and are reviewed by Onwumechili (1967) and Forbes (1981). To reduce the effects of short period disturbances it is customary to low pass the data by computing hourly means. Examples of the hourly means of the $Z$ and $H$ magnetic fields for all stations on January 6, are shown in Figs. 3 to 5. Tabulated hourly means for each station and each of the 16 quiet days can be found in Rigoti (1994).

The latitude dependence of the diurnal variation is evident in Figs. 3 and 4. The magnetograms are stacked according to latitude for the observatories and according to distance $(\mathrm{km})$ from the magnetic equator for the array stations (see also Table 1). Examining the horizontal field variation in Fig. 3 it is seen that at low latitudes, from VAS to TAT, $\Delta H$ presents a single maximum at about noon. As the latitude increases, the noon maximum decreases until it exhibits only a poorly defined double peaked curve at intermediary latitude positions as for SJG and DLR (Fig. 4). At higher latitudes a minimum $\Delta H$ is observed about noon, as at the observatories FRD and BOU.

Diurnal variations of $\Delta Z$ in Fig. 3 show the dominance of the EEJ field across the array from SJP31 to TAT. Here the noon value of $\Delta Z$ is close to zero at the equator (station ARA36), but increases southwards to reach a maximum (downward field in the southern hemisphere) near station SJP31 and decreases northwards, to attain a minimum (upward field) near BRA13. Outside the region EEJ dominates, the noon value of $\Delta Z$ again tends to a maximum in the south (not shown in the figures) and to a minimum in the north, observable perhaps at DLR (Fig. 4) but poorly defined.

The hourly mean values were used to compute the maximum diurnal range (midday average minus midnight average) to be used in the modelling process. Two different definitions of the ranges were employed. The $\mathrm{M}_{4}$ range (Onwumechili, 1967) in which the midday average is calculated from four hours, 10:00 to 13:00, and a modified $\mathrm{M}_{3}$ range, comprising a three hours average, but with the central hour being allowed to vary from day to day in order to coincide with the time of maximum. The midnight average uses the four hours 22:00 to 01:00. The averages are based on local time and centered on the hour. The modified $\mathrm{M}_{3}$ should give a more realistic amplitude estimate and a better fit to the EEJ model on days when fluctuations may distort $\mathrm{M}_{4}$ considerably. The implied averaging process reduces bias from high-frequency disturbances, and also from the day-to-day variability of the time of maximum and asymmetry noted earlier.

To simulate a longitudinal profile we have projected the positions of the array stations on to a line perpendicular to the dip equator. The corresponding relative distances used in the modelling are listed in Table 1. The EEJ exhibits longitudi- 

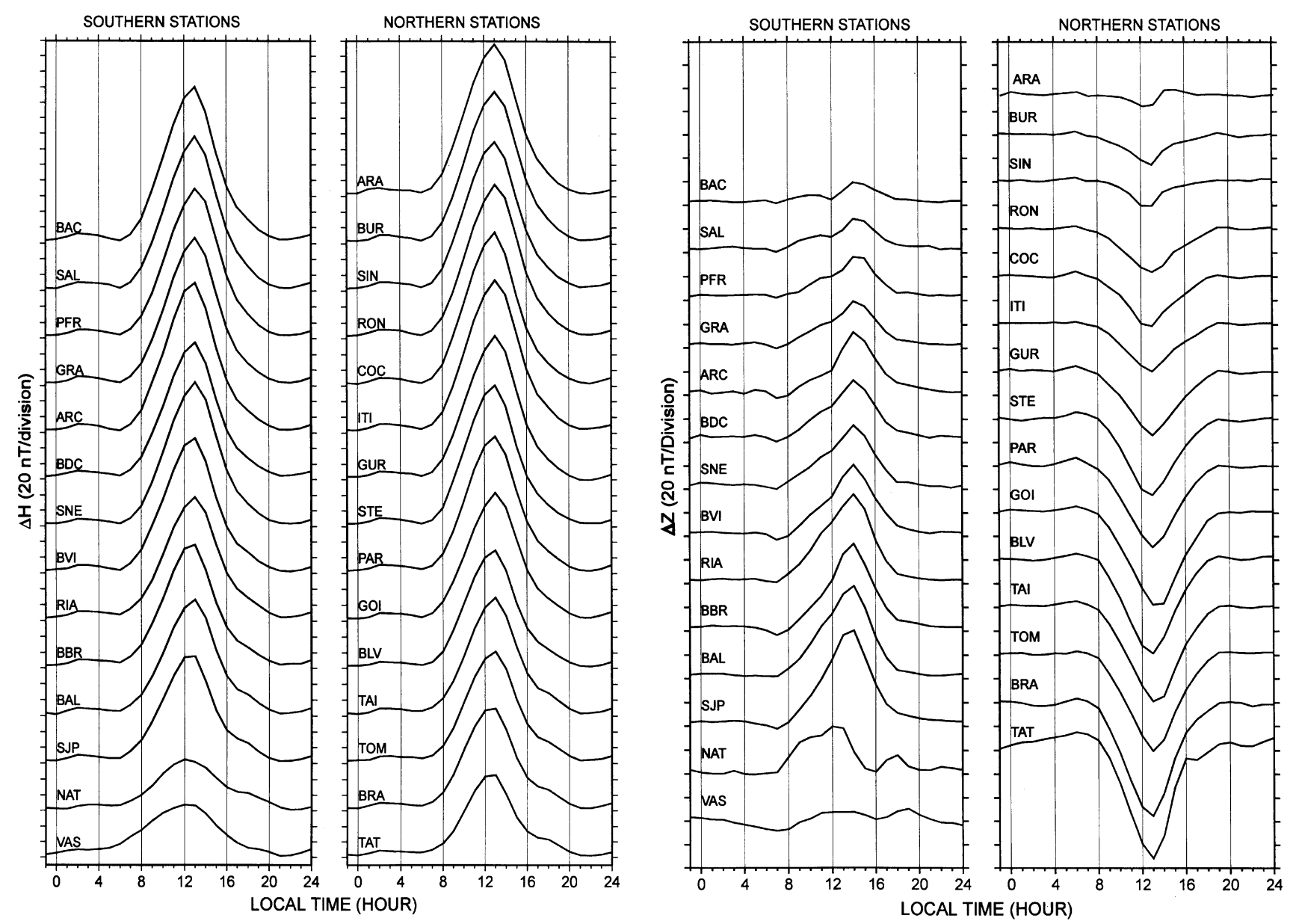

Fig. 3. The diurnal variation on 6 January, 1991 for all Brazilian stations using hourly means. The stations are arranged from top to bottom in order of increasing distance from the magnetic equator. The left hand panel shows the horizontal component and the right hand panel the vertical component.

nal variability and the global conditions change with universal time, but we consider that the small longitude spread of the array of $3^{\circ}$ justifies the procedure, even including Natal, which is the only station available in the southern edge of the EEJ, and which is about $10^{\circ}$ from the center of the array. Several tests, using different profiles of array stations in the modelling, showed no dependence on the longitude. It is also clear from the modelling results, presented below, that there is no correlation with longitude for any misfit to the model. Less satisfactory is the extension of the profile to higher latitudes with the inclusion of the North American observatories (Table 1). However, results show that the global conditions happened to be stable enough during the selected quiet days to allow for a reasonable estimate of the global $S q$ using data from these observatories.

The $S q$ and EEJ current systems are similar in nature and effects, but have different axes of "symmetry". The $S q$ shows the least scatter when plotted as a function of mean latitude (Onwumechili, 1967; Fambitakoye and Mayaud, 1976; Rigoti, 1994) and is therefore assumed to depend on the distance from the mean equator (halfway between the geographic and dip equator). However the fitting of ground observed EEJ fields to ionospheric current distributions, indicate that the EEJ is centred around the dip equator as shown by the present study and by previous similar studies (Chapman, 1951b; Onwumechili, 1967; Fambitakoye and Mayaud, 1976; Duhau and Romanelli, 1979; Hesse, 1982). Of course neither the $S q$ nor EEJ are exactly symmetrical about their respective axes, but for the purpose of fitting simple models describing the current distribution at the time of maximum amplitude on quiet days the assumption of symmetry is justified. Therefore, one should consider two different profiles. One profile that uses the mean latitude as ordinate and is used to estimate $S q$ and another that uses the distance from the magnetic equator. The mean latitudes and the distance from the magnetic equator are listed in Table 1 with the origin assumed to coincide with station ARA36, which is close to the dip equator. The magnetic inclination is obtained from the IGRF for early January 1991.

An example of the extended profile in which the daily ranges $\mathrm{M}_{4}$ are plotted as a function of mean latitude, for 6 January 1991, is shown in Fig. 5. The figure illustrates the relative contributions of the $S q$ variation and the EEJ on the horizontal and vertical field components. The solid line represents the $S q$ variation as obtained from the modelling and the dashed curve represents the EEJ. The different centers of symmetry for the maxima are indicated by the vertical lines. 


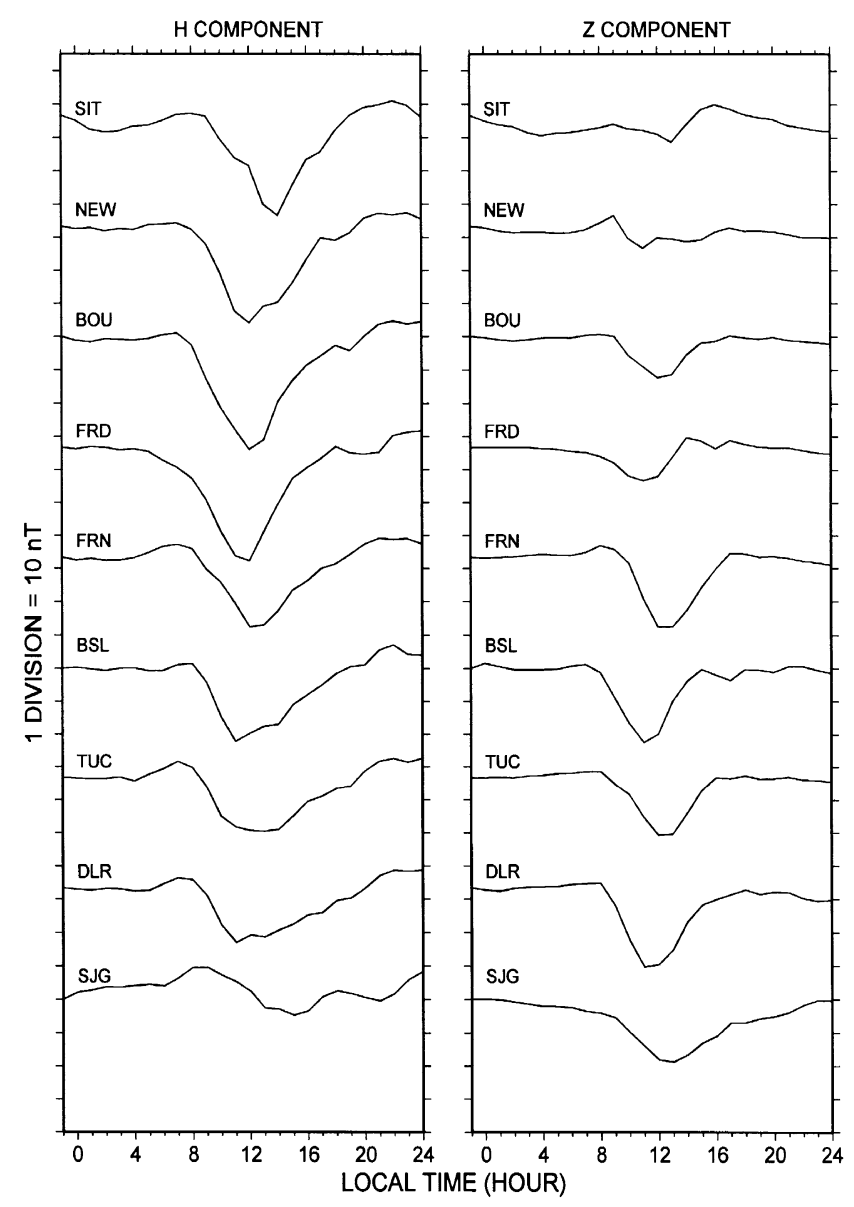

Fig. 4. $\quad H$ and $Z$ diurnal variation (hourly means) on 6 January 1991 for several observatories of the USGS network. The stacked traces are ordered according to the mean latitude, which increases from the bottom to the top of each panel.

\section{Modelling Procedure}

Information about the EEJ may be obtained from ground and high altitude studies. The latter have resulted in detailed physical models and a comprehensive review on the subject is found in Forbes (1981). Ground observations of the magnetic fields associated with the EEJ, provide information on the EEJ morphology, particularly its latitudinal distribution.

The main characteristics of the EEJ were described by Onwumechili (1967) by fitting an equivalent current model to the observed magnetic fields. In such an analysis, only simple currents systems are used such that the surface magnetic field components can be computed from closed expressions. The EEJ current is assumed to flow eastwards along the dip equator in a thin layer. In this layer the current density varies only with latitude and is symmetric about the central axis where the maximum occurs. In the meridional plane, the current density tends to zero at some latitude. Further, the thin layer of currents is assumed to be infinite along the E-W direction. These conditions are appropriate for a N-S profile of the maximum amplitude of the EEJ at noon. Duhau and Romanelli (1979) point out that the thin layer approximation introduces an error of less than $2 \%$ in the derived ground magnetic fields, compared to more realistic or complex current distributions. The reason for such a small error is that
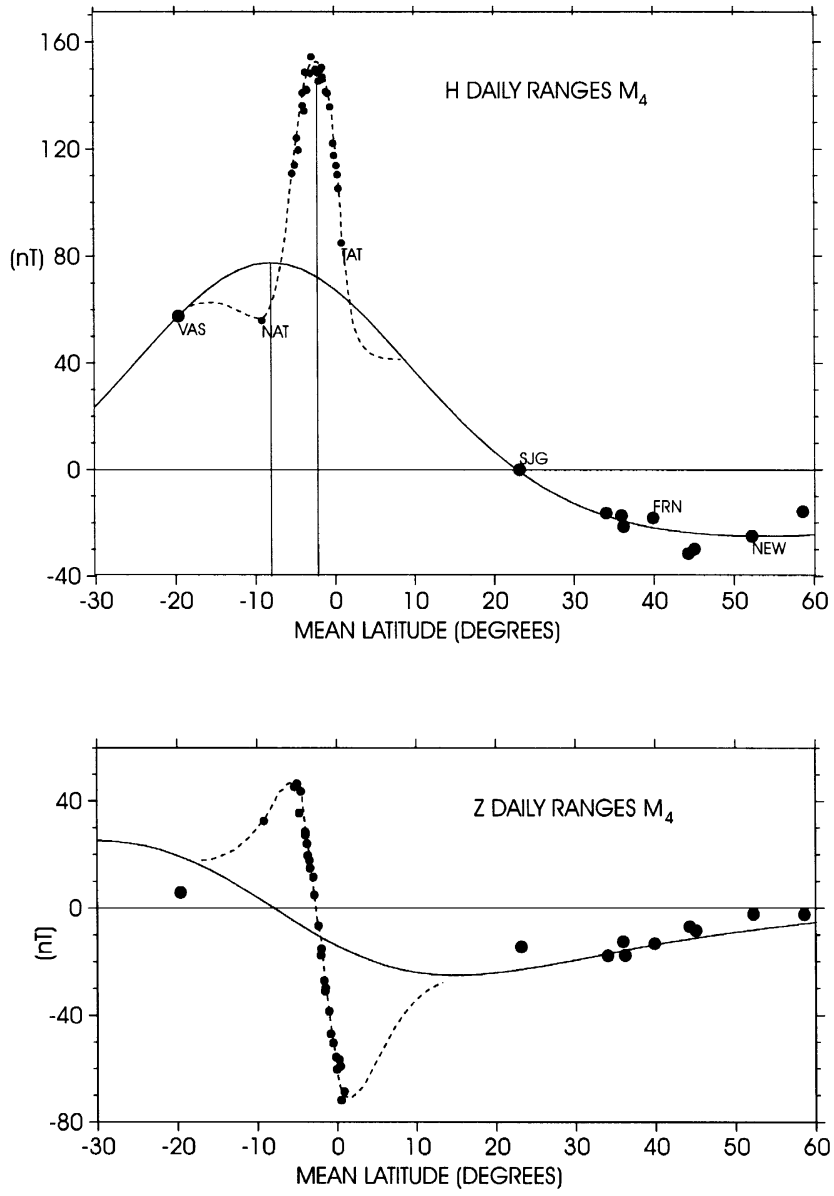

Fig. 5. The daily range M4 of 6 January, 1991, of the $H$ component (top panel) and $Z$ component (bottom panel) as a function of mean latitude. The solid lines represent the $S q$ variation as determined from the inversion and the dotted line the EEJ variation. The two vertical lines mark the latitude for the $S q$ and EEJ maximum. Large circles are the observatories and the small circles the array stations.

the vertical current density profiles are almost symmetrical with respect to the height of the maximum current intensity and the thickness $(\approx 30 \mathrm{~km})$ of the layer where most of the current is flowing is small compared to its height $(\approx 107 \mathrm{~km})$ (Davis et al., 1967).

Historically, different forms of current distribution have been used to derive the EEJ fields that would match ground observations. The parabolic distribution as proposed by Chapman (1951b) and the fourth-degree distributions (Onwumechili, 1967; Fambitakoye and Mayaud, 1976) have proved successful in fitting the observations. The assumption that the current is concentrated in a thin layer, flowing eastwards, varying in intensity only with latitude, implies a thinshell model. However, implicitly, in the height-integration of conductivities or current density, the total net eastward current is accounted for, independently of the vertical structure of the EEJ. Ground observations do not have the sensitivity to discriminate between slightly different shapes of the current distribution (Fambitakoye and Mayaud, 1976), or between different vertical structures (Duhau and Romanelli, 1979). Nor can they readily distinguish the part of the field created by vertical current flow. 
The choice of an EEJ-equivalent current distribution model should then be concerned with:

a) Representing the variation of current density with latitude as close to the real situation as possible, and

b) be simple enough for the magnetic fields it generates to be expressed in close form, so as to allow for a practical inversion of the ground observations.

The immediate consequence of (a) above is that the parameters of intensity and width of the EEJ should be determined to an acceptable level of accuracy by the inversion. Two such models of EEJ-equivalent current distribution, which satisfy conditions (a) and (b) above, were given by Onwumechili (1967) and Fambitakoye and Mayaud (1976). The latter authors compared the results of their current distribution model with the numerical physical model of Richmond (1972). They concluded that the intensity and width parameters in their model have real physical meaning. This conclusion is also valid for Onwumechili's model, since Onwumechili's central positive part of the current is easily shown (Rigoti, 1994) to be equivalent to the distribution of Fambitakoye and Mayaud, for a certain ratio of the central positive to the flank negative currents in Onwumechili's model.

Onwumechili's current model (Onwumechili, 1967) has been chosen for the present study because it accommodates (in a single layer) the negative currents at the EEJ flanks, which can account for the minimum in the northward component of the magnetic field observed $800 \mathrm{~km}$ south of the magnetic equator, at station NAT40 (see Fig. 5). Previous ground based studies have reported on the minima of EEJ's $H$ field at approximately the same distance from the equator (e.g. Chapman, 1951b; Onwumechili, 1967; Fambitakoye et al., 1976; Hesse, 1982). High altitude observations also point to the existence of negative currents in the flanks of the EEJ which can generate the observed $H$ minima on the ground (Maynard, 1967; Cain and Sweeney, 1973; Musmann and Seiler, 1978). Furthermore, physical models predict that the reverse currents at some distance from the axis of the EEJ, responsible for the ground observed $H$ minima, can be generated by a reversal of the vertical polarisation field (Sugiura and Poros, 1969) and severe wind shears (Anandarao and Raghavarao, 1987). Recall that Onwumechili's current distribution is expressed as:

$$
J=J_{0} \frac{a^{2}\left(a^{2}+\alpha x^{2}\right)}{\left(a^{2}+x^{2}\right)^{2}}, \quad \alpha \leq-1
$$

where $J_{0}$ is the maximum current density at the centre of the distribution, $a=\omega(-\alpha)^{1 / 2}$ with $\omega$ as the half width and $\alpha$ the parameter which governs the distribution along a meridian. A negative $\alpha$ causes the current to reverse sign at a certain distance $x$. The minimum in $\Delta H$ as observed at our station NAT is thus expected and it seems appropriate to assume that for the EEJ currents the ratio of the peak westward current at the flanks to the peak eastward current (at the center) is approximately 0.3 as suggested by several previous studies (Musmann and Seiler, 1978; Anandarao and Raghavarao, 1979; Onwumechili et al., 1989). To incorporate this ratio in the model, the parameter $\alpha$ was allowed to vary only slightly around -1.8 in the inversion process. Under certain simplifying assumptions, the northward $X$ and vertical $Z$ magnetic field components generated by the above current distribution are given by:

$$
\begin{aligned}
& \left(\operatorname{sign}_{z}\right) X \\
& =K a \frac{(h+\alpha h+2 \alpha a)(u+b)^{2}+(h+\alpha h+2 a)(h+a)^{2}}{2\left[(u+b)^{2}+(h+a)^{2}\right]^{2}},
\end{aligned}
$$

and

$$
\begin{aligned}
& -\left(\operatorname{sign}_{x}\right) Z \\
& =K a \frac{(u+b)\left[(1+\alpha)(u+b)^{2}+(h+\alpha h+3 a-\alpha a)(h+a)\right]}{2\left[(u+b)^{2}+(h+a)^{2}\right]^{2}},
\end{aligned}
$$

where:

$x$ is the northward distance from the central axis of the current distribution,

$z$, the vertical distance (positive downwards) from the current distribution,

$\operatorname{sign}_{x, z}$ is the sign of the coordinate $x$ or $z$,

$b$, a vertical scale length, related to the half-thickness,

$u$, the magnitude of the northward distance $x$,

$h$, the magnitude of the vertical distance $z$,

$K$, stands for the magnetic field of an infinite current sheet with constant intensity $J_{0}, K=0.2 \pi J_{0}$,

$\alpha$, a dimensionless constant, determining the proportion of westward current in the flanks of the current distribution,

$a$, a constant meridional scale length, related to the half-width $\omega$ as $a=\omega(-\alpha)^{1 / 2}$.

Equations (2) and (3) are used as fitting equations (forward model) in the inversion of the observed $H$ and $Z$ field components of the EEJ and $S q$. Due to the assumptions made in the derivation of these equations, only profiles perpendicular to the axis of the current distribution at the time of maximum around noon can be modelled.

A non-linear least-squares procedure was adapted from Rigoti and Crossley (1987) to invert the $H$ and $Z$ field profiles for the model represented by Eqs. (2) and (3). The parameters to be estimated are $K, a, \alpha$ and the centre of the current distribution $u_{0}$. A height $(h)$ of $110 \mathrm{~km}$ was assumed for the $S q$ current and $107 \mathrm{~km}$ (Davis et al., 1967) for the EEJ. Parameter $(b)$ was set to zero, as if the current was concentrated in an infinitely thin layer. EEJ results have also been computed for $b=9.47 \mathrm{~km}$ (Onwumechili et al., 1989). In Eqs. (2) and (3) " $u$ " is substituted by $\left(u-u_{0}\right)$. The problem is non-linear in the parameters $a$ and $u_{0}$ and the system is overdetermined, i.e. the number of data $(n)$ is larger than the number of parameters $(m)$.

Derivatives of (2) and (3) with respect to each of the parameters form the derivative matrix $\mathbf{A}(n \times m)$, which is factored (e.g. Jackson, 1972) into:

$$
\mathbf{A}=\mathbf{U} \Lambda \mathbf{V}^{\mathrm{t}}
$$

where $\Lambda$ is a diagonal matrix containing the $m$ non-zero singular values $\lambda_{1}, \lambda_{2}, \ldots, \lambda_{m}$ of $\mathbf{A}, \mathbf{U}$ is an orthogonal $(n \times m)$ matrix containing, in the first $m$ rows, the $m$ semiorthonormalized data eigenvalues $(\lambda)$ and $\mathbf{V}$ is an orthogonal matrix containing the $m$ semi-orthonormalized parameter eigenvectors $(v)$. 
With $\Delta \mathbf{C}$ as the vector containing the differences between observed and calculated data at any iteration and $\Delta \mathbf{p}$ as the parameter update vector, the linearised problem $(\Delta \mathbf{C}=$ $\mathbf{A} \Delta \mathbf{p})$ has the solution:

$$
\Delta \mathbf{p}=\mathbf{V} \Lambda^{-1} \mathbf{U}^{\mathrm{t}} \Delta \mathbf{C}
$$

To ensure convergence, solution (5) is modified by introducing an arbitrary factor $K$ to give the damped least-squares solution (Marquardt, 1970; Johansen, 1977):

$$
\Delta p=\sum_{j=1}^{m} \frac{\mathbf{B}_{j} \lambda_{j}}{\left(\lambda_{j}^{2}+K\right)} v_{j},
$$

where $\mathbf{B}=\mathbf{U}^{t} \Delta \mathbf{C}$.

The residual variance (Inman, 1975),

$$
\sigma^{2}=\frac{(\mathbf{D} \Delta \mathbf{C})^{\mathrm{t}} \mathbf{D} \Delta \mathbf{C}}{(n-m)},
$$

was used as a convergence criterion and as a measure of goodness of fit. The data weighting matrix D was taken as the identity matrix, implying constant and uncorrelated data error. With this weighting, at the end of the inversion process, $\sigma^{2}$ gives the precision within which the model fits the observations. If the data were weighted with the real error they contain, which is unknown, the final $\sigma^{2}$ would be equal to one. Once $\sigma^{2}$ is computed, the parameter covariance matrix (Jackson, 1972) can be calculated by:

$$
\operatorname{Cov}(p)=\sigma^{2}\left(\mathbf{V} \Lambda^{-2} \mathbf{V}^{t}\right),
$$

and the root-squared diagonal elements of the covariance matrix give the parameter standard deviations. The more independent a parameter is in the model, the more realistic the standard deviation will be.

The inversion process described above is used to model both $S q$ and EEJ. The difference is in the scale of the problem. For the $S q$, distances are in degrees of mean latitude whereas for the EEJ, distances are in kilometres.

The $S q$ was estimated by fitting the model to the observatories' data, with the constraint that the amplitude of the $S q$ should be such that, after its subtraction from the daily ranges, the resulting EEJ would have a meridional distribution parameter $\alpha$ of -1.8 (Westward/Eastward current about $0.3)$. This step required preliminary inversions of the EEJ daily ranges. After the $S q$ was subtracted from the daily ranges and the remaining EEJ daily ranges were separated into internal and external parts, the latter was inverted to yield the final EEJ model.

A typical example of EEJ inversion results is tabled below. Note that at the final joint inversion of $H$ and $Z$, all four parameters were allowed to vary. At some of the previous stages of the modelling process, $\alpha$ was fixed to a specified value, but at the final joint inversion of the two components, its value would remain -1.8 without any further constraint.

Inversion results for the quiet day of 6 January, 1991 after 6 iterations.

From the singular value structure it is seen that the system is well behaved and close to linearity. Each of the eigenvectors "points" dominantly to one of the four parameters.
Residual variance $=2.97$.

Model parameters

\begin{tabular}{cccc}
\hline$K$ & $\alpha$ & $a$ & $x_{0}$ \\
\hline 105.68 & -1.78 & 676.1 & 17.21 \\
\hline
\end{tabular}

Singular value structure-eigenvalues

\begin{tabular}{cccc}
\hline$\lambda_{1}$ & $\lambda_{2}$ & $\lambda_{3}$ & $\lambda_{4}$ \\
\hline 67.79112 & 3.25186 & 0.09305 & 1.11015 \\
\hline
\end{tabular}

Associate eigenvectors

\begin{tabular}{rrrrr}
\hline$v_{1}$ & \multicolumn{1}{c}{$v_{2}$} & \multicolumn{1}{c}{$v_{3}$} & \multicolumn{1}{c}{$v_{4}$} & \\
\hline-0.01666 & 0.99915 & 0.03753 & -0.00300 & $K$ \\
-0.99985 & -0.01683 & 0.00419 & 0.00036 & $\alpha$ \\
-0.00481 & 0.03746 & -0.99929 & 0.00180 & $a$ \\
0.00032 & 0.00294 & 0.00191 & 0.99999 & $x_{0}$ \\
\hline
\end{tabular}

Parameter covariance matrix

\begin{tabular}{rrccc}
\hline \multicolumn{1}{c}{$K$} & \multicolumn{1}{c}{$\alpha$} & \multicolumn{1}{c}{$a$} & $x_{0}$ & \\
\hline 0.763 & & & & $K$ \\
0.049 & 0.007 & & & $\alpha$ \\
-12.852 & -1.435 & 342.524 & & $a$ \\
0.018 & 0.004 & -0.651 & 2.411 & $x_{0}$ \\
\hline
\end{tabular}

The eigenvalues are all significant, the smallest being associated with the eigenvector which points to the parameter $a$ (meridional scale length). The covariance matrix shows that parameter $a$ presents the largest uncertainty and correlates with $K$ and $\alpha$. However, its standard deviation computed from the respective diagonal element of the covariance is $\pm 18.5 \mathrm{~km}$, which is very small as it represents only $3 \%$ of the value of the parameter. The negative covariance between $a$ and $K$ indicates that one can, to a certain extent, increase the width and reduce the intensity of the EEJ and still maintain the fit to within the data error. The degree of equivalence involving $a, K$ and $\alpha$ was also tested by random search for acceptable solutions around the model estimated by the inversion. It was found that the tolerance for changes in $a$ is less than $10 \%$, i.e. for changes in $a$ larger than $10 \%$ (relative to the value it has at the minimum residual variance) there were no equivalent changes in $K$ and $\alpha$ that were able to adjust the data within the same residual variance.

It is seen in Fig. 5 that the observations map in detail the electrojet in the proximity of the equator but that the profile lacks observations in the region of the tail of the EEJ and its transition to the $S q$ level. There is only one station, NAT40, well positioned in the transition region. Modelling and removal of the $S q$ fields in the equatorial region is difficult, as the recorded fields are the joint responses of EEJ and $S q$. The lack of data just outside the EEJ region increases the problem. To constraint the amplitude of the $S q$ in the inversion, the expected shape (see below) of the EEJ current distribution was used as a priori information. 
Table 2. Solar Quiet parameters.

\begin{tabular}{lcccccccccc}
\hline & \multicolumn{2}{c}{$K(\mathrm{nT})$} & \multicolumn{2}{c}{$\alpha$} & \multicolumn{2}{c}{$a$ (Degree) } & \multicolumn{2}{c}{$x_{0}$ (Degree) } & \multicolumn{2}{c}{$\Delta H_{\text {MAX }}(\mathrm{nT})$} \\
\hline & $\mathrm{M}_{4}$ & $\mathrm{M}_{3}$ & $\mathrm{M}_{4}$ & $\mathrm{M}_{3}$ & $\mathrm{M}_{4}$ & $\mathrm{M}_{3}$ & $\mathrm{M}_{4}$ & $\mathrm{M}_{3}$ & $\mathrm{M}_{4}$ & $\mathrm{M}_{3}$ \\
Mean & 66.6 & 72.3 & -1.9 & 1.9 & 40.4 & 39.9 & -6.1 & -5.5 & 87.8 & 95.1 \\
St. dev. & 13.9 & 15.4 & 0.55 & 0.6 & 5.12 & 5.32 & 2.53 & 2.22 & 18.3 & 20.4 \\
\hline
\end{tabular}

The dashed curve of $\Delta H$ in Fig. 5 delineates the EEJ field superimposed on the $S q$ field. It is seen that the value of $H$ at station NAT40 requires the EEJ's $\Delta H$ to contain a minimum, going well below the $S q$ level. Although the minimum in the EEJ's $\Delta H$ is based on a single station (NAT40), such a minimum has been observed elsewhere (see references quoted earlier). The minimum in $\Delta H$ as observed at station NAT40 is thus expected and it seems appropriate to assume for the EEJ currents that the ratio of the peak westward current (at the flanks) to the peak eastward current (at the centre) is around 30\% (Musmann and Seiler, 1978; Anandarao and Raghavarao, 1979; Onwumechili et al., 1989). In order to incorporate this ratio for the EEJ in the modelling, the peak amplitude $\Delta H$ of the $S q$ was constrained to a certain equatorial amplitude that determines the adequate zero level (background) for the EEJ's $\Delta H$.

\section{Estimate of the Solar Quiet $(S q)$}

For the $S q$, only $H$ data were inverted. The final model $\left(K, \alpha, a, x_{0}, b=0, h=1^{\circ}\right)$ which generates the best $H$ fit was then used to calculate $Z$, by considering that the $S q$ consists of the external (primary) field plus the internal (secondary) field generated by the currents induced in the earth by the external field. It is assumed that the ratio of internal to external contribution is 0.4 (Chapman, 1919). The theoretical $Z$ curves calculated with the model that generated the $S q$ external $H$, multiplied by 0.6 (the internal $Z$ opposes the external), fit the observations reasonably well (see Fig. 6). The vertical component at Vassouras often fits poorly, which is attributed to the strong temperature drift that was evident in the magnetograms.

Figure 6 presents the $S q H$ and $Z$ fields that best fit the observatories' (circles) data. Only the profiles for the $\mathrm{M}_{4}$ ranges are shown, but the $\mathrm{M}_{3}$ ranges are virtually identical. The single observatory appearing in the southern part is Vassouras and the one closest to the equator in the northern portion of the profile is San Juan. Considering that these two observatories are approximately equidistant from the equator, it is clear that the centre of the $S q$ is located in the southern hemisphere, and lies much closer to Vassouras than to San Juan.

Table 2 summarises the inversion results for the $S q$ parameters $K, a, \alpha$ and $x_{0}$ from which the external part of the $S q$ may be computed. To recover the curves that best fit the observations, it is necessary to multiply the results obtained from Eqs. (2) and (3), after substituting the corresponding parameters, by 1.4 and 0.6 respectively. These factors account for the assumed ratio of internal to external parts. Values in the column $\Delta H_{\mathrm{MAX}}$ refer to the peak horizontal field of the $S q$ as it would be recorded (internal + external).

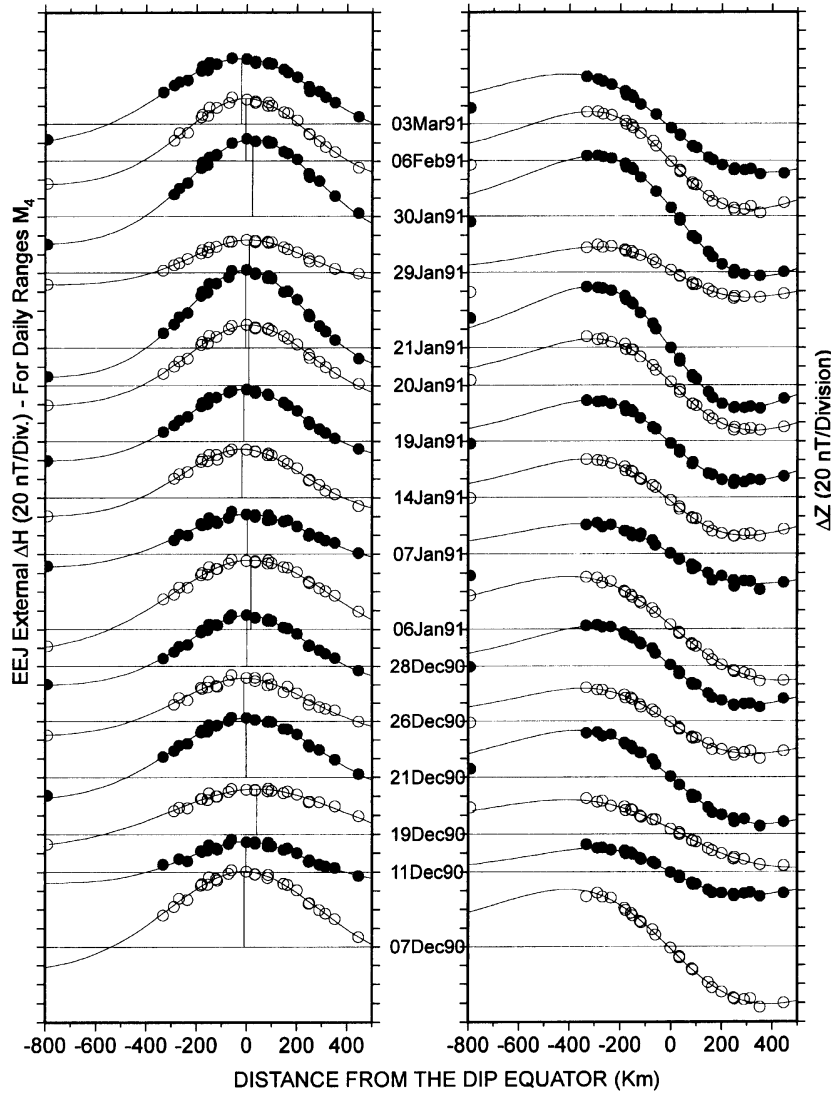

Fig. 6. Solar Quiet latitude profiles. Curves are the theoretical $\Delta H$ and $\Delta Z$ values that best fit the observatories' $\mathrm{M}_{4}$ daily ranges (circles). For clarity's sake dashed or continuous curves and full or empty circles are used alternatively. The horizontal thin mark the zero amplitude level and the vertical ones mark the position of the maximum.

The results show a high degree of consistency between days (Rigoti, 1994). Both daily ranges $\mathrm{M}_{4}$ and $\mathrm{M}_{3}$ produce the same parameters, except for the amplitude ( $K$ and $\left.\Delta H_{\mathrm{MAX}}\right)$ which is about $9 \%$ higher in the case of $\mathrm{M}_{3}$.

Of immediate interest for the study of the EEJ are the $H$ and $Z$ profiles of the $S q$ which can now be extrapolated to the region of the array and subtracted from the observed field to yield the daily ranges caused by the EEJ (external + internal) alone.

\section{The EEJ Internal Part and Observed $Z$ Asym- metry}

The significance of induced currents associated with the EEJ when examined in the latitude profiles of daily ranges (noon maximum) has been controversial. Forbush and 
Casaverde (1961) find that the induction associated with the regular daily variation of the EEJ is compatible with that of an image current at $600 \mathrm{~km}$ depth. Fambitakoye (1973) and Fambitakoye and Mayaud (1973) show that there are image currents associated with the perturbations of the EEJ, but that induction associated with the regular daily variation of the EEJ is negligible. Ducruix et al. (1977) present a theoretical treatment confirming Fambitakoye and Mayaud's observations. Duhau and Romanelli (1979) confirm Forbush and Casaverde's results in Peru. In the region of the present array study, Hesse (1982) reports to have found only a very small internal part related to the EEJ, reflecting an image current at a depth of $1300 \mathrm{~km}$. More recently, Duhau and Osella $(1983,1984,1985)$ find the depth to the highly conducting layer to be at more than a $1000 \mathrm{~km}$ in Africa and Favetto et al. (1992) obtained a depth of $1000 \mathrm{~km}$ under the Indian shield.

The results that follow confirm that there is only a small $(<10 \%$ of the external) internal contribution that can possibly be attributed to the EEJ regular daily variation. Profiles of the internal $H$ and $Z$, as expected for an EEJ image at depth (see Fig. 7), were obtained for only 5 of the 16 quiet days for which the EEJ was successfully modelled. For the remainder days (Rigoti, 1994), either the internal part was too small to be interpreted or it was erratic, but still smaller than $10 \%$ of the external. The inaccuracy in the estimate of the $S q$ and departures from the assumed simple model of current distribution may be the reasons for the lack of consistency in determining the internal part of the EEJ regular daily variation. Fambitakoye (1973) points out that the EEJ internal-external separation is very sensitive to the definition of the $S q$ ( $S_{\mathrm{R}}^{\mathrm{P}}$ in his notation).

The Kertz operator (Kertz, 1954) by means of Hilbert transforms (Siebert and Kertz, 1957) was used for the separation of the EEJ into its internal and external parts. Denoting the reverse sign Hilbert transform of the observed (EEJ part in the daily ranges) $H$ and $Z$ fields by " $K H$ " and " $K Z$ " respectively and using the subscript " $e$ " for external and " $i$ " for internal parts, the separation is based on the following simple relations:

$$
H_{\mathrm{e}}=\frac{1}{2}(H+K Z), \quad H_{\mathrm{i}}=\frac{1}{2}(H-K Z),
$$

and

$$
Z_{\mathrm{e}}=\frac{1}{2}(Z-K H), \quad Z_{\mathrm{i}}=\frac{1}{2}(Z+K H) .
$$

The fitting equations (2) and (3) are a pair of Hilbert transforms. Therefore, if a single model $\left(K, a, \alpha, x_{0}\right)$ substituted into these equations fits both $H$ and $Z$ observations, it means that there is no internal contribution. By inverting $H$ alone using Eq. (2) as the forward problem, $K H$ can be determined by substituting the final model of the $H$ inversion into Eq. (3). Similarly, by inverting $Z$ alone using Eq. (3), $K Z$ can be found by substituting the final model of the $Z$ inversion into Eq. (2). Once $K H$ and $K Z$ have been analytically determined, Eqs. (9) and (10) give the internal part of the two magnetic components.

The $H$ and $Z$ values used in Eqs. (9) and (10) for the computation of the internal parts are the ones that fitted the
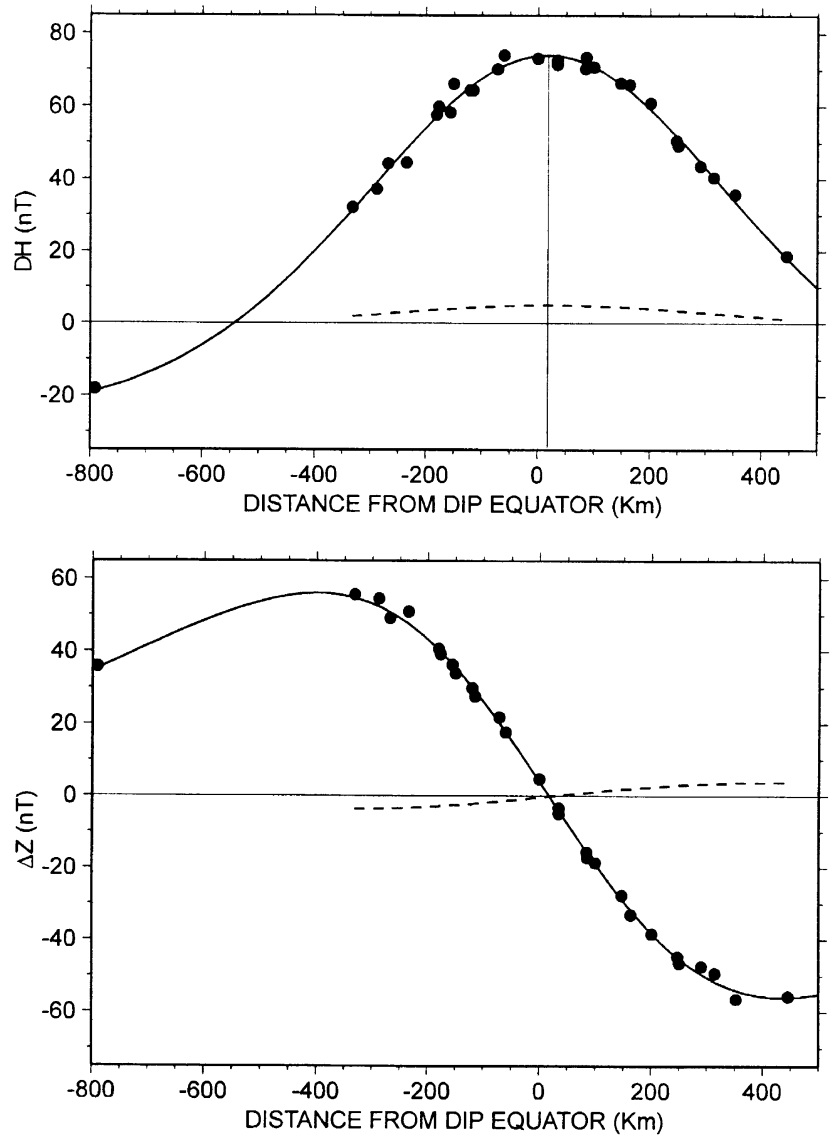

Fig. 7. The EEJ profile on 6 January, 1991. Continuous curves are the theoretical $\Delta H$ and $\Delta Z$ fitting the EEJ external part of the daily ranges $\mathrm{M}_{4}$ (circles) and dashed curves represent the small EEJ internal part.

observations, when the individual $H$ and $Z$ inversions were performed.

Before the inversion, the $Z$ values are corrected for a commonly observed asymmetry (Onwumechili, 1967). Figure 6 shows the triangles marking the position of the $Z$ value at the centre (first approximation) of the EEJ. It is seen that in most cases the estimated $Z$ of the $S q$ passes above the triangle, which means that after subtracting the $S q Z$ from the $Z$ daily ranges, the remaining $Z$ of the EEJ is slightly asymmetric. If the $S q$ fields could have been computed precisely, there would probably be no asymmetry. On some quiet days, like 28 December 1990 and 6 January 1991, $Z$ at the centre of the EEJ is exactly on the $S q Z$ curve, so that it will be zero after the $S q Z$ is subtracted from the $Z$ daily ranges. However, there is generally a need for a correction for the asymmetry in $Z$. To determine the amount $c_{Z}$ (shown in Table 3 ) to be added to the $Z$ data, the observed $Z$ curve is compared to the Hilbert transform of $H$.

\section{Morphology of the Electrojet}

As discussed in Section 4, the meridional distribution parameter $\alpha$ was assumed to have a value around -1.8 which translates into 0.3 ratio of westward to eastward current, accounting for the minima observed at the tails of the EEJ.

For most of the quiet days analysed, the correction of the EEJ daily ranges due to the subtraction of the internal part 
Table 3. Summary of EEJ parameters.

\begin{tabular}{|c|c|c|c|c|c|c|}
\hline \multirow[b]{3}{*}{ Parameter } & \multicolumn{3}{|c|}{$\mathrm{M}_{4}$} & \multicolumn{3}{|c|}{$\mathrm{M}_{3}$} \\
\hline & \multicolumn{2}{|c|}{$b=0 \mathrm{~km}$} & \multirow{2}{*}{$\begin{array}{r}b=9.47 \mathrm{~km} \\
\text { Mean }\end{array}$} & \multicolumn{2}{|c|}{$b=0 \mathrm{~km}$} & \multirow{2}{*}{$\begin{array}{r}b=9.47 \mathrm{~km} \\
\text { Mean }\end{array}$} \\
\hline & Mean & St. dev. & & Mean & St. dev. & \\
\hline$K(\mathrm{nT})$ & 93.6 & 25.0 & 91.8 & 111.6 & 24.4 & 109.4 \\
\hline$\alpha$ & -1.81 & 0.06 & -1.82 & -1.81 & 0.03 & -1.82 \\
\hline$a(\mathrm{~km})$ & 542.0 & 86.5 & 569.3 & 543.9 & 70.3 & 572.4 \\
\hline$x_{0}(\mathrm{~km})$ & 1.48 & 15.93 & 1.76 & 1.67 & 13.12 & 2.05 \\
\hline$H_{\mathrm{MAX}}(\mathrm{nT})$ & 59.7 & 16.3 & 59.6 & 71.3 & 15.9 & 71.3 \\
\hline$\omega(\mathrm{km})$ & 402.9 & 67.0 & 422.4 & 404.3 & 54.9 & 424.3 \\
\hline$J_{0}(\mathrm{~A} / \mathrm{km})$ & 148.94 & 39.85 & 146.05 & 177.7 & 38.86 & 174.1 \\
\hline$J_{\mathrm{MIN}}(\mathrm{A} / \mathrm{km})$ & -43.70 & 12.38 & -42.98 & -51.99 & 11.74 & -51.3 \\
\hline$u_{-} J_{\mathrm{MIN}}(\mathrm{km})$ & 786 & 128 & 825 & 789 & 105 & 829 \\
\hline$J_{\mathrm{MIN}} / J_{0}$ & -0.29 & 0.01 & -0.29 & -0.29 & 0.01 & -0.29 \\
\hline$I+\left(10^{3} \mathrm{~A}\right)$ & 66.9 & 20.5 & 68.9 & 79.8 & 19.8 & 82.2 \\
\hline$Z_{\mathrm{MAX}}(\mathrm{nT})$ & 45.9 & 12.6 & 45.9 & 54.9 & 12.3 & 54.9 \\
\hline$u_{-} Z_{\mathrm{MAX}}(\mathrm{km})$ & 343 & 47 & 349 & 344 & 38 & 351 \\
\hline$u_{-} H_{0}(\mathrm{~km})$ & 452 & 69 & 463 & 454 & 56 & 464 \\
\hline$c_{Z}(\mathrm{nT})$ & 6.9 & 5.6 & 6.9 & 8.7 & 5.4 & 8.7 \\
\hline Res. var. & 3.4 & 1.3 & 4.1 & 3.3 & 0.8 & 4.3 \\
\hline
\end{tabular}

Where:

$H_{\text {MAX }}(\mathrm{nT})$, the peak amplitude of the horizontal field on the ground

$\omega(\mathrm{km})$, the half-width of the current, related to " $a$ " as $a=\omega(-\alpha)^{1 / 2}$

$J_{0}(\mathrm{~A} / \mathrm{km})$, the peak Eastward "current density", related to $K$ as $K=0.2 \pi J_{0}$.

$J_{\mathrm{MIN}}(\mathrm{A} / \mathrm{km})$, the minimum (Westward) "current density" from $J_{\mathrm{MIN}}=J_{0} \alpha^{2} /[4(\alpha-1)]$

$u_{-} J_{\mathrm{MIN}}(\mathrm{km})$, the distance from the current axis to where $J_{\mathrm{MIN}}$ occurs, given by $\left(u_{-} J_{\mathrm{MIN}}\right)^{2}=a^{2}(\alpha-2) / \alpha$.

$\left(J_{\mathrm{MIN}} / J_{0}\right)$, the ratio of the minimum to the maximum current density.

$I+$, the total positive (Eastward) current in Amperes.

$Z_{\mathrm{MAX}}(\mathrm{nT})$, the maximum amplitude of $Z$ on the ground.

$u_{-} Z_{\text {MAX }}(\mathrm{km})$, distance from the centre to where $Z_{\text {MAX }}$ occurs.

$u_{-} H_{0}(\mathrm{~km})$, distance from the centre to where $H$ is zero, before reversing sign.

$c_{Z}$ (nT), the constant added to $Z$ data to correct for the asymmetry.

(Res. var.), the residual variance.

was smaller than $4 \mathrm{nT}$. Nevertheless this small correction improved the fit obtained in the inversion of the external part of the fields. It represents a fine adjustment to the data, such that $H$ and $Z$ latitude profiles better represent a Hilbert transform pair. The general characteristics of EEJ latitude profiles obtained from the joint inversion of the EEJ external $H$ and $Z$ for the 16 quiet days can be seen in Fig. 8 for the $M_{4}$ range (the results for the $\mathrm{M}_{3}$ range are virtually identical (Rigoti, 1994)). These curves represent probably the most detailed mapping of the electrojet ground signatures near the centre of the EEJ reported to date. In contrast to the frequently mentioned difficulties of fitting the $Z$ component, the present results show an excellent fit from the joint inversion of $H$ and $Z$ components. The mean residual variance (Table 3 ) is about 3-4 nT. This means that on average, the model adjusts to the data within 3-4 nT, which is comparable to the observational error.

$Z$ ranges of NAT40 (distance $=-800 \mathrm{~km}$ ), although plotted in Fig. 8 were not included in the inversion because they are generally affected by induction (probably coast-effect). On the other hand, the $H$ component of NAT40, assumed to have negligible induction effect, was very important in the choice of a model which could accommodate the $\Delta H$ minima at the flanks of the electrojet, as observed at this station. Notice that NAT40's $H$ range is always below the line of zero $H$ (level of $S q$ 's $H$ ). In the quiet days of 7 and 11 December 1990 the station NAT40 is not available because its recording started only on 12 December 1990.

Table 3 summarises the morphology of the electrojet, in terms of the model parameters using Onwumechili's notation (Onwumechili et al., 1989).

To illustrate the advantage of ranges $\mathrm{M}_{3}$ with variable central hour over $\mathrm{M}_{4}$, it is interesting to examine how the EEJ builds up, starting early morning, attaining the maximum at about noon and then decaying in the afternoon, to vanish by evening. Figure 9A shows a normal behaviour of the EEJ and Fig. 9B shows a quiet day marked by a morning counterelectrojet (CE). The "hourly ranges" plotted in these figures 


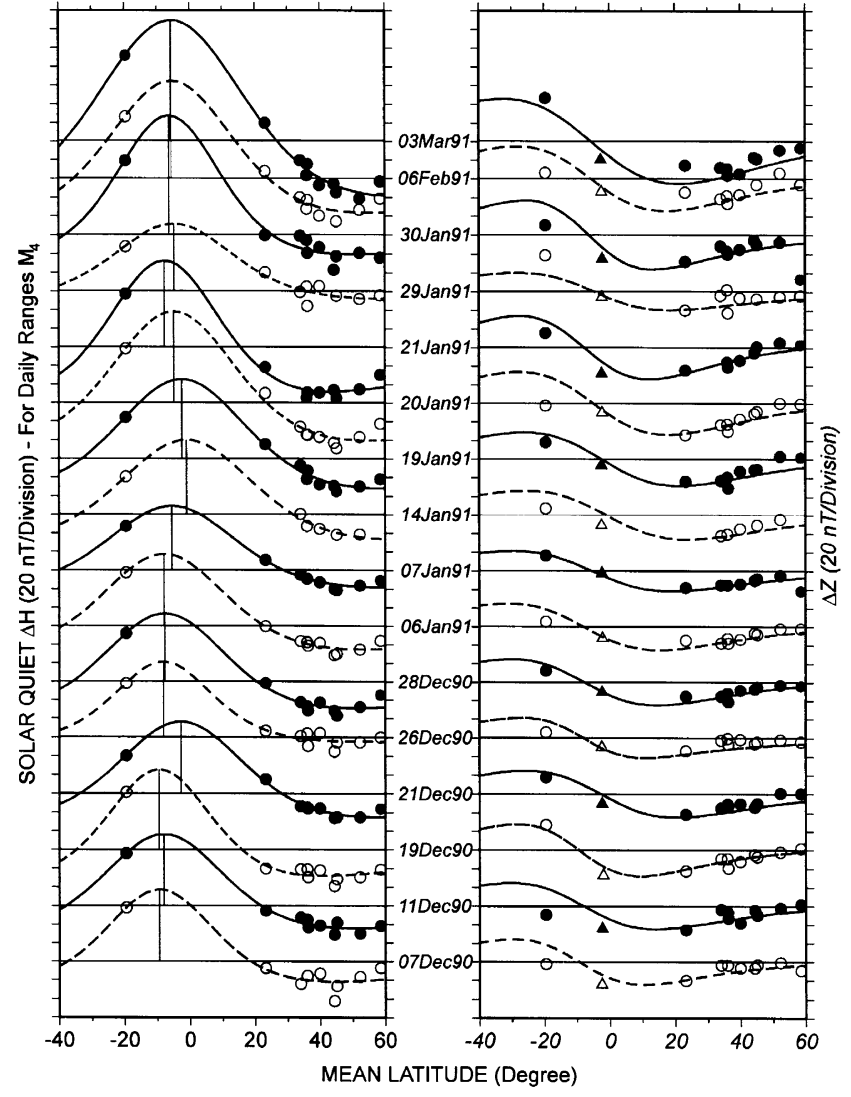

Fig. 8. The EEJ external part of the daily ranges $\mathrm{M}_{4}$ as a function of latitude for the 16 quiet days. The solid (or dashed) curves are the model curves and the circles the observed data.

reflect approximately the contribution of the EEJ alone. The $S q$ determined from daily ranges $\mathrm{M}_{4}$ was shifted up or down to match the value of the hourly range at Vassouras and then was subtracted from the hourly ranges at the array stations. The continuous curves through the $\Delta H$ and $\Delta Z$ data are the result of inversion exercises designed to test the consistency between the EEJ model and the data.

In Fig. 9A an example is shown of the growth and decay of the EEJ profile of what we believe is a normal quiet day (Jan. 6 1991). Until 08:00 hours in the morning the hourly ranges are all close to zero, although a very small amplitude CE can just be detected at 06:00 and 07:00 hours. As the earth rotates with respect to the sun the EEJ fields become clearly noticeable at 9:00 and built to a maximum at 13:00. From there the amplitude decreases to reach a zero level at 18:00. The solid curves are shown only when the fit obtained from the inversion test was reasonable. It is seen that even for this quiet day the model cannot fit $\Delta Z$ at 10:00. This means that a simple model of a current sheet infinitely long in the W-E direction does not explain all the data at this time of this day. The 4 hours period which is more representative of the peak amplitude of the EEJ in this example would be within 11:00 and 15:00, and if the number of hours is limited to three, these would certainly be 12:00, 13:00 and 14:00. $H$ and $Z$ profiles at these hours not only show the largest amplitude but are also more consistent with the model. The traditional $\mathrm{M}_{4}$ daily ranges are thus not always a good choice to represent the noon maximum. Next example makes this point clearer.

Despite the morning counter-electrojet in 7 January 1991 (Fig. 9B) an intense eastward electrojet develops after 11:00 with the maximum very well defined between 12:00 and 14:00 hours. On the other hand, at 10:00, the CE is still present and its effect on the 4-hours average is to decrease the amplitude of $H$. For comparison, the traditional $\mathrm{M}_{4}$ ranges give the EEJ maximum $\Delta H$ of $42.4 \mathrm{nT}$ while the $\mathrm{M}_{3}$ (12:00 to $14: 00)$ ranges give $77.5 \mathrm{nT}$, a $45 \%$ difference.

\section{Summary and Conclusions}

The present array study has enabled us to map the EEJ magnetic fields in considerable detail in an area straddling the magnetic equator. Insufficient data at the tails of the EEJ and its transition to the $S q$ was overcome by making the assumption that the westward current at the flanks of the EEJ is $30 \%$ of the central eastward current. While there is some support for this assumption (Musmann and Seiler, 1978; Anandarao and Raghavarao, 1979; Onwumechili et al., 1989) it is not necessarily universally accepted (Fambitakoye and Mayaud, 1976). However, when used as a priori information in a combined $S q$ and EEJ inversion it constrains the amplitude of the $S q$ and allowes for its extrapolation to the equatorial region. The result is that for the selected 16 quiet days, the inversions show a very good fit of both $H$ and $Z$ field data to Onwumechili's (1967) model for the EEJ current distribution. $H$ and $Z$ daily ranges of the external EEJ were jointly inverted for the 16 quiet days.

For most days, a small correction for an asymmetry in $Z$ was necessary before the internal/external separation and the final inversion could be performed. It is suggested that the accuracy can be significantly improved if more stations are available along the N-S profile up to and including the latitude where the $S q H$ describes a minimum.

All computations and inversions were carried out using both the $\mathrm{M}_{4}$ and $\mathrm{M}_{3}$ ranges. Comparison (Rigoti, 1994) of the results suggest that if there are sufficient quiet days available for analysis, it may not matter which of the two ranges is used. However in cases of limited choice, range $\mathrm{M}_{3}$ may give a more realistic estimate of the amplitude of the EEJ.

The mean value of the total eastward current was found to be $67,000 \pm 20,000 \mathrm{~A}$ based on the daily ranges $\mathrm{M}_{4}$ and $80,000 \pm 20,000 \mathrm{~A}$ for $\mathrm{M}_{3}$. From a profile study at about the same longitude in NE Brazil, Hesse (1982) found intensities in the range of 20,000 to 70,000 A, and Onwumechili et al. (1989) determined, from satellite data, a value between 50,000 and 61,000 A for a longitude sector that includes the area of the present study. These results compare well, but the spread in estimates reflects daily and seasonal variability.

The half width of the EEJ eastward (positive) was determined as $403 \pm 67 \mathrm{~km}$, which again compares very well with the 350 to $400 \mathrm{~km}$ obtained by Hesse (1982).

The high density of stations near the dip equator provided by the array allowed for an accurate mapping of the centre of the EEJ. The average position of the centre was $21 \mathrm{~km}$ south of the dip equator, with a variability expressed by the standard deviation of the mean as $\pm 16 \mathrm{~km}$. The maximum distance observed was $62 \mathrm{~km}$. 


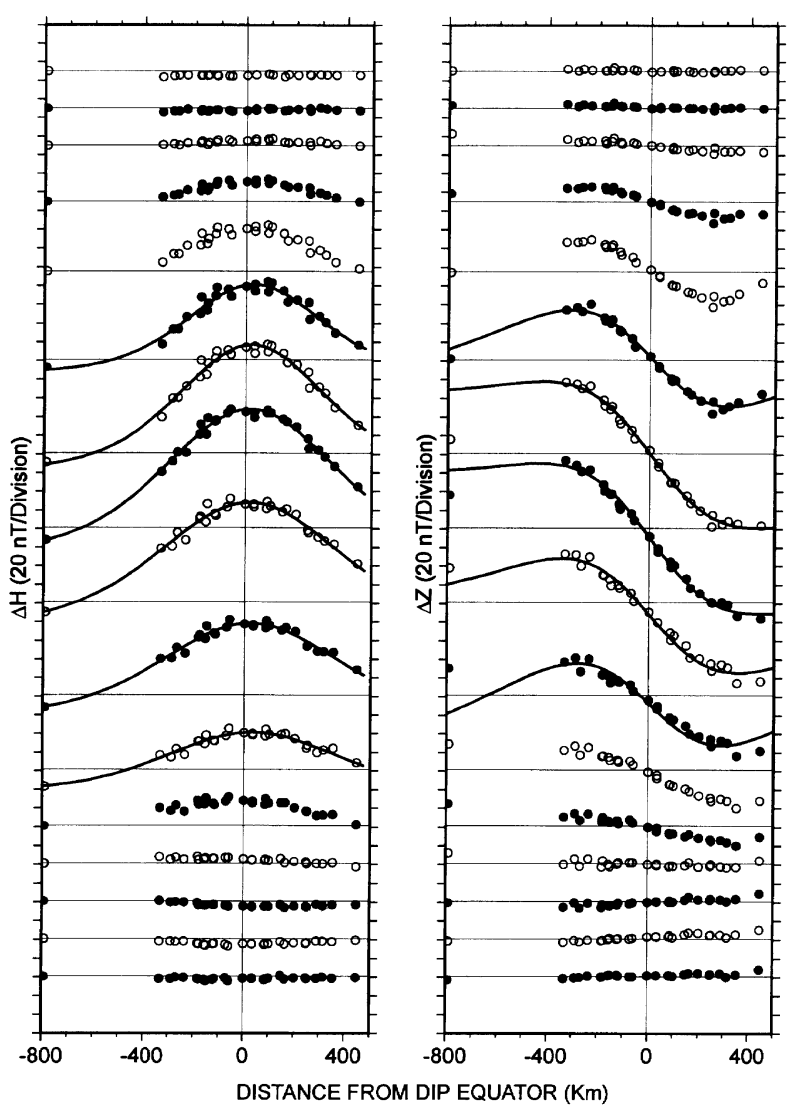

(A) 6 January, 1991
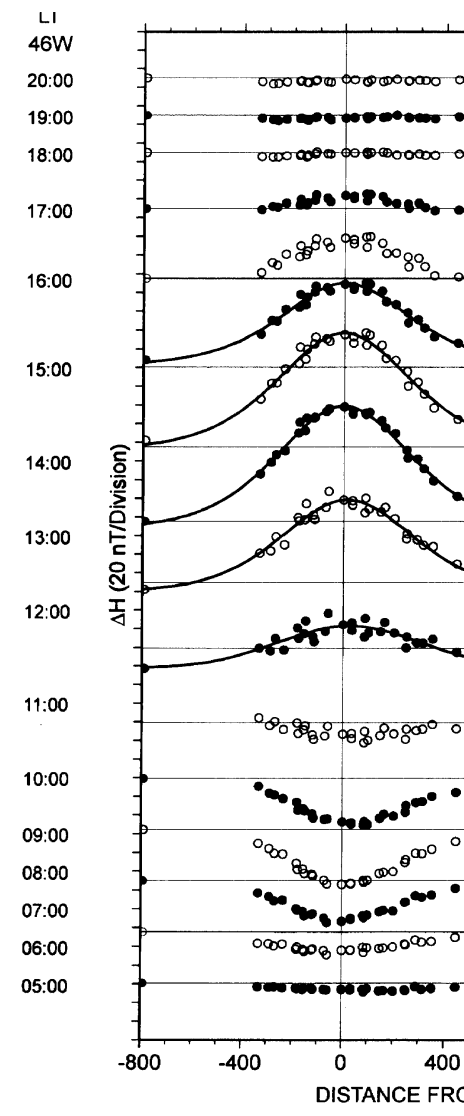

(B) 7 January, 1991

Fig. 9. (A) Hourly mean profiles of the EEJ on a typical quiet day (6 January 1991). The solid lines are the model fit. (B) Hourly profiles of the EEJ on a quiet day with the occurrence of a morning counter-electrojet (7 January 1991).

A possible correlation between the variability of EEJ and $S q$ was analysed (Rigoti, 1994) in terms of current intensity and movement of the centres. Only a slight tendency for a linear relation between the intensity of the EEJ and $S q$ was found. The movements of $S q$ and EEJ centres did not show any clear correlation.

Acknowledgments. We thank B. R. Arora for constructive criticism and suggestions. Data from permanent magnetic observatories were kindly supplied by the Observatorio Nacional (ON) and by the USGS. We have benefited from the plotting routines (GMT System) of Wessels and Smith (1995). The study was carried out while the first author (A. R.), was engaged in a Ph.D. study with the financial support of CNPq - Conselho Nacional de Desenvolvimento Científico e Tecnológico and The Flinders University of South Australia. The deployment of the array was possible thanks to a cooperation between the Instituto Nacional de Pesquisas Espaciais (INPE) and The Flinders University. The field work was funded by FAPESP (Process 90/1024-7) and would not have been a success without the unstinting help and participation of Mr. Adauto Gouveia Motta of INPE/Natal, and Mr. Niomar Viegas de Carvalho e Oliveira of the Secretariat of Science and Technology, State of Maranhao. The Australian participation was supported by the Australian Research Council. The editor thanks O. Saka and another referee for their assistance in evaluating this paper.

\section{References}

Anandarao, B. G. and R. Raghavarao, Effects of vertical shears in the zonal winds on the electrojet, Space Res., 19, 283-286, 1979.
Anandarao, B. G. and R. Raghavarao, Structural changes in the currents and fields of the equatorial electrojet due to zonal and meridional winds, $J$. Geophys. Res., 92, 2514-2526, 1987.

Bartels, J. and H. F. Johnston, Geomagnetic tides in horizontal intensity at Huancayo, P. I., J. Geophys. Res., 45, 269-308, 1940a.

Bartels, J. and H. F. Johnston, Geomagnetic tides in horizontal intensity at Huancayo, P. II., J. Geophys. Res., 45, 485-512, 1940 b.

Cain, J. C. and R. E. Sweeney, The POGO data, J. Atmos. Terr. Phys., 35, 1231-1247, 1973.

Chamalaun, F. H. and J. D. McKnight, A New Zealand wide magnetometer array study, J. Geomag. Geoelectr., 45, 741-759, 1993.

Chamalaun, F. H. and R. Walker, A microprocessor based digital fluxgate magnetometer for geomagnetic deep sounding studies, J. Geomag. Geoelectr., 34, 491-507, 1982.

Chapman, S., The solar and lunar variation of the earth's magnetism, Philos. Trans. R. Soc. London, A, 218, 1-118, 1919.

Chapman, S., The abnormal daily variation of horizontal force at Huancayo and in Uganda, Terrest. Magn. Atmos. Electr., 53, 247-250, 1948.

Chapman, S., Some phenomena of the upper atmosphere, Proc. Phys. Soc. London, B, 64, 833-843, 1951a.

Chapman, S., The equatorial electrojet as detected from the abnormal electric current distribution above Huancayo, Peru, and elsewhere, Arch. Meteorol. Geophys. Bioclimatol., A, 4, 368-390, 1951 b.

Coffey, H. E., Geomagnetic and solar data, edited by Helen E. Coffey, J. Geophys. Res., 96, 5885, 5887, 9835, 11647, 14195, 1991.

Davis, T. N., K. Burrows, and J. D. Stolarik, A latitude survey of the equatorial electrojet with rocket-borne magnetometer, J. Geophys. Res., 72, 1845-1861, 1967.

Ducruix, J., V. Courtillot, and J. L. Le Mouel, On the induction effects associated with the equatorial electrojet, J. Geophys. Res., 82, 335-351, 1977.

Duhau, S. and A. M. Osella, Depth of the non-conducting layer at the 
Nigerian dip equator, J. Geophys. Res., 88, 5523-5527, 1983.

Duhau, S. and A. M. Osella, Depth of the non-conducting layer at Central Africa, J. Geomag. Geoelectr., 36, 113-120, 1984.

Duhau, S. and A. M. Osella, Determinacion de la profundidad de la capa no conductora en Nigeria y Africa Central, Geophysics, 12, 167-173, 1985.

Duhau, S. and L. Romanelli, Electromagnetic induction at the South American geomagnetic equator as determined from measured ionospheric currents, J. Geophys. Res., 84, 1849-1854, 1979.

Egedal, J., The magnetic diurnal variation of the horizontal force near the magnetic equator, Terrest. Magn. Atmos. Electr., 52, 449-451, 1947.

Egedal, J., Daily variation of the horizontal magnetic force at the magnetic equator, Nature, 161, 443-444, 1948.

Fambitakoye, O., Effets induits par l'electrojet équatorial au centre de I'Afrique, Ann. Geophys., 29, 149-169, 1973.

Fambitakoye, O. and P. N. Mayaud, Remarques sur la séparation des effets externes et internes à Huancayo, Ann. Geophys., 29, 168-169, 1973.

Fambitakoye, O. and P. N. Mayaud, Equatorial electrojet and regular daily variation $\mathrm{S}_{\mathrm{R}}-\mathrm{I}$, A determination of the equatorial electrojet parameters, $J$. Atmos. Terr. Phys., 38, 1-17, 1976.

Fambitakoye, O., P. N. Mayaud, and A. D. Richmond, Equatorial electrojet and regular daily variation $\mathrm{S}_{\mathrm{R}}-\mathrm{III}$, Comparison of observations with a physical model, J. Atmos. Terr. Phys., 38, 113-121, 1976.

Favetto, A., A. M. Osella, and S. Duhau, Depth of the conductosphere under the Indian shield, Phys. Earth Planet. Inter., 71, 180-188, 1992.

Forbes, J. M., The equatorial electrojet, Rev. Geophys. Space Phys., 19, 469-504, 1981.

Forbush, S. E. and M. Casaverde, The Equatorial Electrojet in Peru, p. 620, Carnegie Inst. Wash. Publ., 1961.

Hesse, D., An investigation of the equatorial electrojet by means of groundbased magnetic measurements in Brazil, Ann. Geophys., 38, 315-320, 1982.

Inman, J. R., Resistivity inversion with ridge regression, Geophysics, 40 , 798-817, 1975.

Jackson, D. D., Interpretation of inaccurate, insufficient and inconsistent data, Geophys. J. R. Astron. Soc., 28, 97-109, 1972.

Johansen, H. K., A man/computer interpretation system for resistivity soundings over a horizontally stratified earth, Geophys. Prosp., 25, 667-691, 1977.

Kane, R. P., Longitudinal difference in the $S q$ profiles in the South American region, J. Atmos. Terr. Phys., 49, 439-441, 1987.

Kane, R. P. and N. B. Trivedi, Influence of northern and southern hemisphere $S q$ current systems on equatorial magnetic variations, J. Atmos. Terr. Phys., 42, 303-305, 1980.

Kane, R. P. and N. B. Trivedi, Comparison of equatorial electrojet char- acteristics at Huancayo and Eusebio (Fortaleza) in the South American region, J. Atmos. Terr. Phys., 44, 785-792, 1982.

Kane, R. P. and N. B. Trivedi, Equatorial electrojet movements at Huancayo and Eusebio (Fortaleza) on selected quiet days, J. Geomag. Geoelectr., 37, 1-9, 1985.

Kertz, W., Modelle für erdmagnetisch induzierte elektrische Ströme im Untergrund, Nachr. Akad. Wiss. Göttingen, 5, Math.-Phys. Kl., 101-110, 1954

Marquardt, D. W., Generalized inverses, ridge regression, biased linear estimation and nonlinear estimation, Technometrics, 12, 591-612, 1970.

Maynard, N. C., Measurements of ionospheric currents off the coast of Peru, J. Geophys. Res., 72, 1863-1875, 1967.

Musmann, G. and E. Seiler, Detection of meridional currents in the equatorial ionosphere, J. Geophys., 44, 357-372, 1978.

Onwumechili, C. A., Geomagnetic variations in the equatorial zone, in Physics of Geomagnetic Phenomena, edited by S. Matsushita and W. H. Campbell, pp. 425-507, Academic Press, New York, 1967.

Onwumechili, C. A., P. C. Ozoemena, and C. E. Agu, Landmark values of equatorial electrojet current and magnetic field along a meridian near noon, J. Geomag. Geoelectr., 41, 443-459, 1989.

Richmond, A. D., Numerical model of the equatorial electrojet, Rep AFCRL-72-0668, ERP 421, Air Force Cambridge Res. Lab., Hanscom AFB, Bedford, Mass, 1972.

Rigoti, A., Geomagnetic array study of the EEJ in NE Brazil, Ph.D. Thesis, Flinders Univ. of South Australia, 1994.

Rigoti, A. and D. J. Crossley, Reduction of ambiguity in geoelectric models using multiple data sets, Revista Brasileira de Geofisica, 5, 29-41, 1987.

Siebert, M. and W. Kertz, Zur Zerlegung eines lokalen erdmagnetischen Feldes in äußeren und inneren. Anteil, Nachr. Akad. Wiss. Göttingen, Math.-Phys. Kl., 87-112, 1957.

Stoerzel, A., Estimation of geomagnetic transfer functions from nonuniform magnetic fields induced by the equatorial electrojet. A method to determine static shifts in magnetotelluric data, J. Geophys. Res., 101, 17917-17926, 1996.

Sugiura, M. and D. J. Poros, An improved model equatorial electrojet with a meridional current system, J. Geophys. Res., 74, 4026-4034, 1969.

Wessels, P. and W. H. F. Smith, New version of the Generic Mapping Tools released, EOS Trans. $A G U$, electronic supplement, http://www.agu. org/eos_elec95154e.html, 1995.

A. Rigoti (e-mail: rigoti@setuva.geologia.ufpr.br), F. H. Chamalaun, N. B. Trivedi, and A. L. Padilha 